is naturaleza 


\section{NATURALEZA Y LIBERTAD}

Revista de estudios interdisciplinares

Número 1

Málaga, 2012

Esta revista es accesible on-line en el siguiente portal: http://grupo.us.es/naturalezayl/ 


\section{Naturaleza y Libertad}

Revista de estudios interdisciplinares

Número 1

Directores: Juan Arana, Universidad de Sevilla; Juan José Padial, Universidad de Málaga; Francisco Rodríguez Valls, Universidad de Sevilla.

Secretaria: Avelina Cecilia Lafuente, Universidad de Sevilla.

Consejo de Redacción: José Luis González Quirós, Universidad Juan Carlos I, Madrid; Francisco Soler, Universität Dortmunt / Universidad de Sevilla; Pedro Jesús Teruel. Universidad CEU Cardenal Herrera; Héctor Velázquez, Universidad Panamericana, México.

Consejo Editorial: Mariano Alvarez, Real Academia de Ciencia Morales y Políticas; Allan Franklin, University of Colorado; Michael Heller, Universidad Pontificia de Cracovia; Manfred Stöcker, Universität Bremen; William Stoeger, University of Arizona.

Consejo Asesor: Rafael Andrés Alemañ Berenguer. Universidad M. Hernández de Elche; Juan Ramón Álvarez, Universidad de León; Luciano Espinosa, Universidad de Salamanca; Miguel Espinoza, Université de Strasbourg; José Manuel Giménez Amaya, Universidad de Navarra; Karim Gherab Martín, Urbana University, Illinois; Martín López Corredoira, Instituto Astrofísico de Canarias; Alfredo Marcos, Universidad de Valladolid; Javier Monserrat, Universidad Autónoma de Madrid; Leopoldo Prieto, Colegio Mayor San Pablo, Madrid; Ana Rioja, Universidad Complutense, Madrid. Madrid; José Luis Rodríguez Recio, Universidad Complutense, Madrid; Javier Serrano, TEC Monterrey (México); Hugo Viciana, Université

Paris I; Claudia Vanney, Universidad Austral, Buenos Aires; José Domingo Vilaplana, Huelva.

\section{Redacción y Secretaría:}

Naturaleza y Libertad. Revista de estudios interdisciplinares. Departamento de Filosofía y Lógica. Calle Camilo José Cela s.n. E-41018 Sevilla.

Depósito Legal: MA2112-2012

๔ 954.55.77.57 Fax: 954.55.16.78. E-mail: jarana@us.es

๑ Naturaleza y Libertad. Revista de Filosofía, 2012 


\section{ÍNDICE}

MANIFIESTO

\section{ESTUDIOS}

Rafael Andrés Alemañ Berenguer. Universidad Miguel Hernández de Elche

La relación mente-materia y el monismo neutral.

Fernando García-Cano Lizcano. Ciudad Real

Evolucionismo y utopia de género

Miguel Ángel Herrero. Universidad Politécnica de Madrid

Instrumentalismo y realismo en la física de James C. Maxwell...

Juan Miguel Suay Belenguer. UNED

La mente mecánica.

José Luis Yepes Hita. Universidad de Murcia

Los «Anales de Física» de L.W. Gilbert.

DisCUSIONES

Francisco José Soler Gil. Universidad de Sevilla - T. Universität Dortmund

¿Se puede naturalizar la epistemología?

Antonio Diéguez. Universidad de Málaga

La opción naturalista. Una respuesta a Francisco Soler

Francisco José Soler Gil. Universidad de Sevilla - T. Universität Dortmund

¿Qué menos que un milagro podría salvar la epistemología naturalista? .265

Antonio Diéguez. Universidad de Málaga

Filosofía sin milagros. Comentarios finales a la contrarréplica de Francisco Soler ...273

CRÍTICA DE LIBROS

Pedro Jesús Teruel, Filosofia y ciencia en Hipatia, (Ángel Martínez Sánchez) . 285 Noticias y COMENTARIOS

Miguel Palomo, Universidad de Sevilla

Si no hay cuerpo, no hay mente: una discusión sobre consciencia y libertad. 


\title{
EVOLUCIONISMO Y UTOPÍA DE GÉNERO
}

\author{
Fernando García-Cano Lizcano \\ Ciudad Real
}

\begin{abstract}
Resumen: Durante el siglo XX tanto el cientifismo, como el darwinismo social hicieron un uso ideológico de la teoría científica de la evolución. En opinión del autor, esas ideologías, junto a otras — como los distintos tipos de totalitarismoestán generando nuevas ideologías que acechan a las sociedades avanzadas. Este nuevo pensamiento dominante es una amalgama de transhumanismo, ideología de género y laicismo. Es necesario que la filosofía ejerza una nueva crítica de las ideologías.
\end{abstract}

Palabras clave: Evolucionismo, género, ideología, transhumanismo, laicismo.

\begin{abstract}
In the $20^{\text {th }}$ century the scientificism as well as the social darwinism made an ideological use of the scientific theory of evolution. According to the author, those ideologies and other ones such as the different types of totalitarism, are generating new ideologies that threaten the developed societies. This new political correctness is a mixture of transhumanism, gender ideology and laicism. These new ideologies should be critized by philosophy.
\end{abstract}

Key words: theory of evolution, ideologie, transhumanism, laicism.

Recibido: 16/02/2011. Aprobado: 10/12/2011.

Las diversas teorías de la evolución del ser humano que se han sucedido desde el siglo XIX a nuestros días no han hecho sino corroborar que estamos ante algo más que una hipótesis, ya que nos 
Naturaleza y Libertad. Revista de estudios interdisciplinares. Número 1, 2012. ISSN: 2254-9668

encontramos ante una teoría verdaderamente científica, que como toda teoría - epistemológicamente hablando- "es una elaboración metacientífica, diferente de los resultados de la observación, pero que es homogénea con ellos"1. Calificar de "metacientíficos" los resultados de las observaciones experimentales interdisciplinares llevados a cabo por ciencias como la genética, la paleontología y la arqueología no deja de llamar la atención sobre la sutil distinción que hay entre ciencia y filosofía, que está a la base de las relaciones que ambas mantienen desde sus orígenes.

\section{LA ANTROPOLOGÍA FILOSÓFICA Y LOS DATOS CIENTÍFICOS SOBRE LA EVOLUCIÓN}

Esa distinción es fundamental a la hora de intentar una comprensión cabal del hombre, que no se presta a ser sólo científicamente estudiado (antropología científica), sino integralmente conocido (antropología filosófica). Entre las intenciones que llevaron a Max Scheler a escribir en 1928 su famosa obra El puesto del hombre en el cosmos estuvieron sobre todo estas dos:

Posibilitar la integración de todos los conocimientos sobre el ser humano que las distintas disciplinas estudian de modo parcelado: la medicina, la psicología, la sociología...

1 Cf. J. Pablo II, “Discurso a la Academia Pontificia de las Ciencias” (24 de octubre de 1996): Acta Apostolicae Sedis 89, 1997: 186-190. 
Mostrar la distancia insalvable que separa al hombre de los animales, por más que el primero provenga de la evolución de especies animales inferiores a él.

Sigue siendo un reto realizar esa tarea integradora que Scheler creyó necesaria y que lleva a considerarle el iniciador de la antropología filosófica, al menos de la elaborada en el siglo XX, porque a inicios del siglo XXI sigue estando muy difundida una comprensión reductiva del hombre, sobre el que nadie negará que es fruto de la evolución, pero no sólo eso, sino también de un salto cualitativo en esa evolución que no puede explicarse más que filosóficamente. Las opciones filosóficas para explicar ese salto son dos: materialismo y espiritualismo. $\mathrm{O}$ bien se considera que la materia es capaz de autoorganizarse de tal manera que no se necesita de ninguna realidad inmaterial para explicar las capacidades neuronales del humano, o por el contrario se opta por la explicación abierta a la trascendencia que explica esas capacidades desde una realidad inmaterial, a la que clásicamente se ha denominado alma.

Lo cierto y verdad es que ambas posturas no son el resultado "científico" de los hechos comprobables experimentalmente, sino "saltos filosóficos" explicativos más allá de los datos, que llegan hasta donde llegan y no pueden demostrar ni el materialismo, ni el espiritualismo. Quienes creen en el supuesto materialismo científico olvidan que no es posible demostrar experimentalmente la inexistencia de lo que, por su naturaleza, escapa al método experimental: el espíritu. Quienes, por el contrario, piensan que el espiritualismo está científi- 
camente demostrado incurren en el mismo error epistemológico: dar por demostrado experimentalmente lo que no puede serlo nunca. Hay nociones que por su propia naturaleza quedan, y siempre quedarán, fuera del ámbito de la ciencia experimental. Entre ellas están las de creación, Dios y alma. En el caso concreto de la creación la oposición entre creación y evolución es una idea artificiosa y carente de rigor científico ya que, por una parte, estos términos se corresponden con procesos conceptualmente independientes: creación significa donación de la existencia y evolución consiste en la modificación de la existencia. Por otra parte, el ámbito de la ciencia experimental es el de los conceptos naturales, como el de evolución de la materia, no conceptos metafísicos, como el de creación ${ }^{2}$.

A pesar de que no es tan difícil comprender la delimitación de los distintos estatutos epistemológicos de la ciencia experimental y de la filosofía, sigue siendo muy frecuente su "mezcla con confusión”, tanto por parte de científicos que dan el paso a lanzar interpretaciones filosóficas como si fuesen "ciencia experimental", como por parte de filósofos que ignoran las aportaciones de las ciencias y más que filosofar con modestia, creen poder considerar sus reflexiones metafísicas al mismo nivel epistemológico que el de las comprobaciones experimentales. 
Naturaleza y Libertad. Revista de estudios interdisciplinares. Número 1, 2012. ISSN: 2254-9668

\section{ANTROPOLOGÍAS REDUCCIONISTAS DE GRAN INFLUJO} MEDIÁTICO

En el debate cultural que provocan estas posturas se pueden señalar como infractores del mismo error metodológico a los cientifistas y a los creacionistas radicales. Las últimas versiones del cientifismo materialista proceden del neurobiologismo que afirma la inexistencia del alma como una verdad "científicamente" demostrada. El creacionismo radical se ha reavivado a raíz de la Teoría del diseño inteligente formulada por el bioquímico Michael Behe en su libro La caja negra de Darwin $^{3}$. Sostiene este autor como una hipótesis científica y filosófica que hay procesos biológicos que no pueden explicarse sólo por el azar, por lo que - en su opinión - hay que admitir una finalidad en la naturaleza y, como consecuencia, un diseñador inteligente, que en última instancia sería un Creador...

No es fácil que junto a las problemáticas relaciones entre ciencia y filosofía se unan las de la religión con ambas. Este tercer factor, en el fondo, queda englobado en la filosofía, puesto que a pesar de que determinados credos religiosos monoteístas se basan en una revelación (Judaísmo, Cristianismo e Islam), las cuestiones de "teología fundamental" son más filosóficas que dogmáticas. Por desgracia la interpretación de los primeros capítulos del libro del Génesis han sido

3 Behe, M., La caja negra de Darwin. El reto de la bioquímica a la evolución, Andrés Bello, Barcelona, 1999. 
literalistas hasta bien entrado el siglo XX y ese déficit de una adecuada hermenéutica no se supera en una generación, ni en dos, sino que costará mucho tiempo que deje de ser un tópico para muchos creyentes lo que abiertamente siguen pensando: que su fe se contrapone a la evolución o a la teoría del big-bang. Con todo, los pasos que se han dado en la pastoral bíblica dentro de la Iglesia Católica son cada vez más importantes y este es un momento en el que justamente se apunta en la dirección de consolidar una lectura correcta de la Sagrada Escritura, dentro de la Tradición y en diálogo abierto con la cultura y ciencia de nuestro tiempo ${ }^{4}$.

Conocidos los datos fundamentales que el neodarwinismo aporta sobre la evolución humana y de los que F. J. Ayala es un buen representante $^{5}$, es claro que se produjo tanto un proceso de hominización (biológico), como un proceso de humanización (cultural). Si el linaje humano se separó del de los chimpancés hace 8 millones de años, el Homo sapiens sapiens existe desde hace unos 130.000 años y la famosa "Eva negra" creó un linaje que se extendió por el mundo hace unos 100.000 años. Sin embargo, la aparición de las primeras civilizaciones se sitúa hace tan sólo 8000 años. Lo decisivo me parece que es ese momento en el que el cuerpo de un hominoide empezó a ser el de un hombre, no sólo por su caracteres morfológicos diferenciales del resto

4 Cf. Benedicto XVI, Exhortación postsinodal Verbum Domini, Madrid, Paulinas, 2010.

5 Ayala, F. J., La teoría de la evolución. De Darwin a los últimos avances de la genética, Madrid, Temas de Hoy, 1994. 
de los animales, sino por su principio vital, es decir por su alma o espíritu, que hizo que también su cuerpo adquiriera una dignidad propia y que se situara en un orden radicalmente distinto al de los animales.

No sé cómo llamar a ese momento en el que del hominoide se pasa al hombre, pero filosóficamente creo que es la cuestión central que remite a una causa de ese "cambio sustancial" y que exige una explicación convincente. Es obvio, como ya se ha dicho, que las respuestas filosóficas pueden ser dos: inmanencia o trascendencia. Son las dos opciones metafísicas intelectuales posibles en todas las grandes cuestiones, igualmente respetables filosóficamente hablando, pero ¿igualmente verdaderas? ¿qué nos inclina realmente a optar por la inmanencia o por la trascendencia a la hora de darnos una explicación filosófica de los hechos experimentales que la ciencia nos suministra, hoy por hoy, con la teoría de la evolución? ¿qué les inclina a los científicos por una u otra opción filosófica, que no científica, puesto que ninguna de las dos son ciencia, sino metaciencia, esto es filosofía?

El revival del enfrentamiento entre creacionistas radicales y evolucionistas materialistas en USA, durante la década de los '80 del pasado siglo, propició que volvieran a confundirse las cosas en términos parecidos a los que ya protagonizara Cuvier, en el siglo XIX, con su teoría de los sucesivos catastrofismos: ver la evolución como contrapuesta a la creación. Lo cierto es que, acotando y delimitando acertadamente los conceptos, esa contraposición es falsa y no por ello sigue estando presente en muchas personas, como ya se ha apuntado. ¿Qué propició ese 
revival? La utilización ideológica por parte del materialismo de la teoría darwiniana. Un buen representante actual de esa utilización es Richard Dawkins ${ }^{6}$, que comenzó su trayectoria intelectual con seriedad $\mathrm{y}$ ha ido derivando en sus últimas publicaciones hacia lo que algunos califican como "un divulgador de festival" (Evandro Agazzi) ${ }^{7}$.

\section{LA RELACIÓN ADECUADA ENTRE FILOSOFÍA Y CIENCIA EN EL CAMPO DE LA ANTROPOLOGÍA}

Resulta clarificador señalar, como hace Artigas, que "no existe la alternativa 'evolución-creación', como si se tratara de dos posturas entre las que se ha de elegir. Se puede admitir la evolución y, al mismo tiempo, la creación divina. Basta advertir que el problema de la evolución se ha de abordar mediante el método científico-experimental, mientras que la necesidad de admitir la creación divina responde a razonamientos metafísicos".

6 Dawkins, R., El relojero ciego, Barcelona, Labor, 1989.

7 Cf. Los documentales sobre El origen del hombre, Madrid, Goya Producciones, 2009, en los que aparecen intervenciones de reputados especialistas de distintas disciplinas (paleontólogos, genetistas, biólogos, filósofos y teólogos). Entre los filósofos que participan en estos documentales destacan las intervenciones de Juan Arana y Evandro Agazzi, autor —este último- entre otros libros de Agazzi, E., El bien, el mal y la ciencia. Las dimensiones éticas de la empresa cientifico-tecnológica, Madrid, Tecnos, 1996. Cf. Hahn, S.-Wiker, B., Dawkins en observación. Una critica al nuevo ateísmo, Madrid, Rialp, 2011.

8 Artigas, M., Las fronteras del evolucionismo, Pamplona, Eunsa, 2004: 118. 
Por desgracia esa clara distinción entre ciencia y filosofía no ha sido reforzada por la última versión del creacionismo radical que se ha convertido en la llamada Teoría del Diseño Inteligente, también ya mencionada. Es una teoría filosófica, que no puede considerarse científica. Tiene por tanto su utilidad en el terreno de la filosofía, pero no puede pretender saltar la línea de demarcación que separa el método metafísico con respecto al método científico-experimental. Habría que evitar las extrapolaciones ilegítimas de la ciencia experimental fuera de su ámbito, al igual que las de la filosofía fuera del suyo. Mantener esa relación y respetuosa distancia no es fácil ni para científicos, ni para filósofos.

Pero me planteaba antes si materialismo y espiritualismo, siendo opciones intelectuales respetables, son igualmente verdaderas. Es aquí donde habría que ejercitar el verdadero arte del debate filosófico al que no estamos muy acostumbrados, porque las diferencias ideológicas entre ambas posturas son muy fuertes y sus consecuencias prácticas también ${ }^{9}$. De todas formas, como señala Landucci, hay que distinguir entre un evolucionismo espontáneo y materialista, para el cual las diversas formas vivientes son puro efecto casual y ciego de las fuerza físico-químicas, y un evolucionismo creacionista y teísta, que admite que la evolución se debe a capacidades que el creador ha puesto en la

9 Cf. Soler Gil, F.; López Corredoira, M., ¿̇Dios o materia? Un debate sobre cosmología, ciencia y religión, Barcelona, Áltera, 2008. El libro está prologado por el profesor Juan Arana, de la Universidad de Sevilla. 
materia y a determinadas intervenciones directas en las transiciones fundamentales, como por ejemplo la aparición de la racionalidad humana. En opinión de Landucci el creyente puede barajar las dos hipótesis a nivel biológico, mientras que el ateo sólo puede optar por la evolución espontánea, como hace por ejemplo Jean Rostand ${ }^{10}$.

En ese sentido, comenta nuevamente Artigas, que "muchos no advierten que la existencia de un Dios creador es necesaria, que la podemos conocer por razonamiento, y que no entra en conflicto con ningún aspecto de la ciencia experimental, ni se dan cuenta de que la necesaria intervención divina para crear el alma espiritual, y la continua acción divina en el curso de la evolución tampoco entran en colisión con las ciencias"11. Pero esto es apelar a planteamientos filosóficos que se atrevan a considerarse verdaderos, frente a otros falsos.

Por eso concluye Artigas:

...toda afirmación de que la naturaleza es creativa en sentido estricto, o de que el universo es autosuficiente, o de que el espíritu puede proceder de la materia, o de que no es necesaria la creación divina para explicar la existencia de la naturaleza, salen fuera del ámbito científico experimental. Se trata de afirmaciones filosóficas, y además son falsas, y su falsedad se puede mostrar con argumentos estrictamente racionales. Las afirmaciones experimentales nunca llegarán al nivel en que se encuentran esas afirmaciones, ya que necesariamente se limitan a los aspectos de la

10 Landucci, P. C., "Il mito darvinista" en Studi Cattolici, luglio 1983: 462.

11 Artigas, 2004: 118-119. 
realidad que pueden someterse de algún modo al control espiritual, y éste no es el caso ni de la creación ni del espíritu ${ }^{12}$.

Llegados a este punto hay que afirmar, con Udías, que el cambio de los hominoides al ser humano "se ha dado de forma gradual en los hombres primitivos y no es detectable en sí, sino sólo por sus consecuencias... La transición del animal al hombre se da con una cierta continuidad, pero también en discontinuidad. Habría que aceptar, además, la existencia de una cierta 'infancia' del hombre, en la que las características humana, aunque ya presentes, no están del todo desarrolladas. Estas características humanas nacen de la existencia en el hombre de una dimensión espiritual no reducible a la mera materia. La presencia de esta dimensión marcaría el inicio de la existencia del hombre, que se produce en un momento que no podemos fijar con exactitud en el proceso evolutivo", porque "a la ciencia, que sólo examina lo observable y de algún modo cuantificable, se le escapa en sí misma esta dimensión"13.

La comprensión de la evolución, por tanto, reclama una explicación filosófica de la misma y es justamente ahí desde donde puede partir una cierta metafísica que se apoye en los datos científicos de la evolución y que se plantee preguntas estrictamente filosóficas como las de quién soy, de dónde vengo y adónde voy... Esas preguntas se las hace

12 Artigas, 2004: 125.

13 Udías, A., Ciencia y religión. Dos visiones del mundo, Santander, Sal Terrae, 2010: 319-320. 
o se las puede hacer el hombre, sea científico o no, y se las responde no la ciencia sólo, sino también y fundamentalmente la filosofía.

Se llega así a la conclusión de que

...el concepto alma es irrenunciable para toda antropología humanista desde el momento en se convenga en designar en dicho concepto, como mínimo, la diferencia cualitativa, entitativa, que (según los humanismos) destaca al hombre de cualquier otra realidad mundana. Entendida como función de la singularidad de lo humano, la noción de alma sería compatible, en principio, con todos aquellos materialismos que no nivelen lo humano por el rasero de lo biológico o lo físico. Decir 'alma' (o 'mente', o 'espíritu') equivaldría a decir materia autotrascendiéndose realmente hacia lo nuevo, lo distinto, lo antológicamente más rico y superior ${ }^{14}$.

Aunque estas palabras de Ruiz de la Peña puedan encerrar ciertas concesiones irenistas a modelos antropológicos monistas, más que integracionistas (alma-cuerpo), lo cierto es que, efectivamente, la postura por la que él mismo se decanta es la sostenida por Santo Tomás de Aquino, para quien "el hombre consiste en la unión sustancial del alma y la materia prima, y no del alma y el cuerpo".

Según este autor,

...mientras que esta segunda fórmula — unión del alma y el cuerpo- parece sobreentender que el cuerpo preexiste a la unión con el alma (o a su función

14 Ruiz de la Peña, J. L., Las nuevas antropologias. Un reto a la teología, Santander, Sal Terrae, 1983: 214. 
Naturaleza y Libertad. Revista de estudios interdisciplinares. Número 1, 2012. ISSN: 2254-9668

informante), resignándose así a la admisión de la posible existencia por separado de ambas entidades en el plano físico, real concreto, el teorema tomista (anima forma materiae primae) desplaza la tensión espíritu-materia del plano físico al metafísico, del nivel del ser real-concreto al nivel de los principios del ser. Lo que existe realmente es lo unido; en el hombre concreto no hay espíritu por un lado y materia por otro. El espíritu en el hombre deviene alma, que no es un espíritu puro, sino la forma de la materia. La materia en el hombre deviene cuerpo, que no es una materia bruta, sino la informada por el $\mathrm{alma}^{15}$.

\section{TRES NUEVOS RIESGOS DE REDUCCIONISMO ANTROPOLÓGICO} PARA EL SIGLO XXI.

Tras los reduccionismos biologicistas a que dieron origen las distintas teorías evolucionistas, una vez caídas las utopías del siglo XX en la emblemática fecha de 1989, parece que la herencia cultural del llamado siglo breve (1a Guerra mundial de 1914 - Caída del muro de Berlín en 1989) es un conjunto de nuevas ideologías que, con raíces culturales diversas, han logrado entretejer un proyecto identitario para la nueva izquierda mundial, entendiéndola como un proyecto que comparten partidos políticos de ambos signos, tanto liberales, como demócratas en terminología anglosajona. La proyección política de esas ideologías resulta evidente en las propuestas de determinados gobiernos, sean de izquierdas o de derechas.

La nueva ingeniería social, como un revival del evolucionismo social de Spencer, parece empeñada en realizar la definitiva revolución cultu- 
ral, que se sustentaría en tres pilares: el transhumanismo, la ideología de género y el laicismo. La conjunción de esos factores constituye una especie de auténtica nueva revolución comunista o si se prefiere de la evolución del comunismo ${ }^{16}$, si bien esa hipótesis necesitaría ser probada como algo más que una sugestiva intuición ${ }^{17}$.

En cualquier caso la presencia de esa tríada de elementos en la base ideológica del pensamiento dominante parece suficientemente constatable a cualquier observador atento y por ello resulta interesante bucear en cada uno de ellos para poder apuntalar un análisis crítico de las nuevas ideologías dominantes en la cultura actual. Que la encíclica Spes Salvi, de Benedicto XVI, incluya la crítica a las ideologías como un factor necesario para sostener y alimentar la esperanza, no debe pasar inadvertido para quien tenga en cuenta los análisis de ese documento magisterial. Entre la bibliografía más reciente en torno a la conmemoración de los 40 años de mayo del 68 hay títulos tan sintomáticos de ese renacer de las ideologías como el escrito por Rafael del Aguila ${ }^{18}$.

16 Cf. Vattimo, G., Ecce comu. Cómo se vuelve a ser lo que se era, Barcelona, Paidós, 2009.

17 Cf. Trujillo, L., La mujer y el dragón, Ciudad Real, Publicaciones del Instituto Beato Narciso Estenaga, 2008. Me reconozco deudor del planteamiento expuesto por este autor en la citada publicación, que recoge una Lección Inaugural de Curso que pronunció en el Seminario Diocesano de C. Real el 10 de octubre de 2008.

18 Águila, R. del, Crítica de las ideologías. El peligro de los ideales, Madrid, Taurus, 2008. 
a) El transhumanismo

Cuando Heidegger escribió su famosa Carta sobre el humanismo a mediados del siglo XX estaba suscitando un debate académico que todavía sigue abierto, pero sobre todo anticipaba una de las temáticas que más interesan a la revolución biotecnológica de inicios del siglo XXI. El tránsito de los intentos de clonación humana hacia los nuevos métodos de eugenesia ha sido tan veloz que, en el transcurso de apenas una década, el horizonte de la propia antropología filosófica se ha visto obligado a medirse en las nuevas fronteras con el mundo animal y con el proyecto gran simio ${ }^{19}$. Lograr que la máxima pascaliana - "el hombre supera al propio hombre" - se realice en un nuevo sentido parece el objetivo de toda la revolución de la ingeniería genética contemporánea. Sin escrúpulos éticos, a pesar de las serias advertencias de voces tan autorizadas y poco religiosas como la de $\operatorname{Habermas}^{20}$, la carrera investigadora trata de conquistar nuevos ciborg que pudieran hacer realidad lo que hasta ahora sólo han sido películas tan geniales como impensables, al estilo de la clásica "Los niños de Brasil" o la más recientes de "Inteligencia artificial" o "Avatar"

19 Cf. Prieto, L., El hombre y el animal, Madrid, Bac, 2008.

20 Habermas, J., El futuro de la naturaleza bumana, Barcelona, Paidós, 2001.

21 Para una presentación del posthumanismo en el cine actual resulta muy útil el artículo de Savagnone, G., "Posthumanismo y cine" en Ballesteros, J., Fernández, E., (ed.), Biotecnologia y posthumanismo, Cizur Mayor, Thomson-Aranzadi, 2007: 189214. 
El hombre está empeñado en superar su propia naturaleza por la vía de la aspiración a un nuevo hombre, que le permita lograr ese transhumanismo en el que queden superados los condicionantes básicos de una naturaleza en última instancia mortal, amén de frágil, enfermiza y contingente. Tal vez una relectura de la tentación inicial de "ser como Dios, pero sin Dios" admita una adecuada trasposición a los terrenos de la investigación biotecnológica ${ }^{22}$ que pretenden algo más que sanar, curar o prevenir enfermedades, sino sencillamente dar con esa fórmula que permita la inmortalidad, deseo de todas las épocas culturales, que tan sugestivamente se puede encontrar formulado en obras literarias como el Fausto de Goethe.

Lo novedoso de los intentos actuales de ese transhumanismo es que parece arrastrar con él la lucha política, a través de su vinculación a la ideología de género, que no representaría más que un demostración fáctica de lo que hoy ya es viable: definirse sexualmente a la carta a lo largo de la propia vida y exigir la abolición de la diferencia en el terreno sexual.

b) La ideología de género

Los peligros y el alcance de la ideología de género son algo que, ya en 1998, el fallecido Oscar Alzamora Revoredo ${ }^{23}$ trató cómo réplica al informe de Dale O’Leary, titulado La deconstrucción de la mujer. 
Títulos más recientes como el de Judith Butler ${ }^{24}$ dan idea de cómo la ideología de género ha ido evolucionado en su propio interior hacia posturas cada vez más radicales ${ }^{25}$. Ese radicalismo es desenmascarado con acierto por algunos de sus críticos, entre los que cabe situar la contribuciones de Jesús Trillo ${ }^{26}$ o Tony Anatrella; en ellas se da información actualizada de cómo se ha ido imponiendo en los gobiernos occidentales este requisito de lo políticamente correcto que consiste en la aceptación acrítica de todos y cada uno de los postulados de esta auténtica revolución sexual, que algunos autores prefieren denominar críticamente pansexualismo ${ }^{27}$.

24 Butler, J., El género en disputa. El feminismo y la subversión de la identidad, Barcelona, Paidós, 2007. De esta autora hay ya varios libros traducidos al castellano, así como algunos introductorios a su pensamiento, como el de Femenias, M.L., Judith Butler. Introducción a su lectura, Catálogos Editora S.R.I, 2003. Se trata de una filósofa postfeminista y postestructuralista y una de las más notables teóricas de los "queer studies", que es profesora Maxine Elliot en el Departamento de Retórica y Literatura Comparada de la Universidad de Berkeley.

25 Cf. Edelman, L, No Future: Queer Theory and the Death Drive, Dirham and London, Duke University Press, 2004.

26 Trillo-Figueroa, J., La revolución silenciosa, Madrid, Libros libres, 2008. Autor también de La ideología invisible, Madrid, Libro libres, 2007, así como de un análisis del peligro totalitario que encierra la propuesta actual de la $\mathrm{EpC}$ en el sistema educativo: Una tentación totalitaria. Educación para la ciudadanía, Pamplona, Eunsa, 2008.

27 Pérez-Soba, J. J., "El pansexualismo y su incidencia en el matrimonio y la familia" en AA.VV. Diálogos de Teología Almudí, no 6, Edicep, 2004: 85-110. 
En opinión de Pérez-Soba "la novedad última de este proceso que ha dado más fuerza al pansexualismo actual ha sido el empeño político internacional de imponer un modelo específico de comprender la sexualidad. Se ha hecho además como una propuesta de alcance universal, incluso exigida a todos los países como un requisito necesario para obtener las ayudas que precisan para su desarrollo".

Y apostilla:

\begin{abstract}
...no podemos ignorar este factor porque tiene una repercusión decisiva para la evangelización. En el tema sexual, 'la teoría de género' propugnada por los poderes políticos y culturales ha encontrado como principal oposición organizada a la Iglesia Católica. La reacción primera de estos poderosos, que ha llegado a configurar una estrategia explícita, ha sido la de desprestigiarla ante el mundo con todos los medios a su disposición. No es algo que se aprecie del todo desde la perspectiva parcial de cada país, pero tiene un peso decisivo en los medios de comunicación en un mundo globalizado de un modo que en muchos casos puede considerarse como avasallante ${ }^{28}$.
\end{abstract}

El reto cultural es tan enorme que no exige sólo la denuncia de los atropellos o desviaciones respecto a una recta razón, sino la propuesta de una auténtica cultura del amor y la familia por parte de la Iglesia y de la sociedad ${ }^{29}$.

28 Pérez-Soba, 2004: 104-105.

29 Tanto la Instrucción pastoral de la CEE, La familia, santuario de la vida y esperanza de la sociedad (2001), como el Directorio de la pastoral familiar de la Iglesia en España (2003) contienen no sólo elementos críticos respecto a la perniciosa ideología de 
El asedio y derribo cultural de la Iglesia Católica que lleva a cabo la cultura dominante es de tales dimensiones internacionales, en materia de género $\mathrm{y}$ derechos reproductivos, que las mismas organizaciones de la ONU y la Unión Europea parecen ser portadoras de una ideología anticristiana ${ }^{30}$.

c) E1 laicismo

La preocupación por la adecuada relación de las religiones con los estados en el inicio del siglo XXI es compartida cada vez por un mayor número de instancias sociales, políticas, religiosas y culturales. Precisamente esa fue la temática de las XIII Jornadas de la Asociación de Letrados del Tribunal Constitucional, cuyas actas acaban de publicarse $^{31}$. En esas Jornadas la ponencia marco fue pronunciada por Dionisio Llamazares, Director de la Cátedra "Laicidad y Libertades Públicas" de la Universidad Carlos III de Madrid ${ }^{32}$, en la que se puede encontrar una actualizada exposición del proyecto laicista que se está desarrollando en España con la intención de adecuar el marco legisla-

género, sino también elementos propositivos para ofrecer a la Iglesia y a la sociedad vías de salida ante esta alarmante situación, que permite "afirmar que en la sociedad española de nuestros días posiblemente la fuente principal de problemas humanos sean los relativos al matrimonio y la familia" (Directorio, $\mathrm{n}^{\circ} 14$ ).

30 Rocella, E.; Scaraffia, L., Contra el cristianismo. La ONU y la Unión europea como nueva ideología, Madrid, Ediciones Cristiandad, 2008.

31 Estado y religión en la Europa del siglo XXI, Madrid, Centro de Estudios Políticos y Constitucionales, Cuadernos y Debates, no 187, 2008.

32 Ibidem.: 13-81. 
tivo y social a la realidad europea en el terreno de la libertad religiosa. Se entiende así por qué desde el inicio de su exposición el profesor Llamazares considera que "la laicidad es el objetivo hacia el que apunta el laicismo como proceso histórico y, como resultado de un proceso histórico, no es ningún dogma sino una manera de ser el Estado con concreciones distintas, según tiempos y lugares: no tiene los mismos matices en unos lugares u otros, ni el grado y formas de evolución son los mismos. Separación entre Iglesia y Estado y neutralidad religiosa de este son sus señas de identidad"33.

$\mathrm{Si}$ bien la exposición aludida, titulada "Libertad religiosa, aconfesionalidad, laicismo y cooperación con las confesiones religiosas en la Europa del siglo XXI", presenta una orientación claramente prolaicista, lo hace desde la convicción reseñada de que éste es un proceso histórico necesario para ajustar las cuentas con la historia y llegar a una laicidad, que hoy por hoy no existe como tal. No es extraño que en el debate que siguió a esta ponencia se le replicara que "el laicismo es una manifestación extrema de la secularización", más que "un paso obligado en el proceso que conduce a la laicidad" que hubiera que pagar como peaje inevitable ${ }^{34}$.

Al margen de la valoración que merezca cada uno de los posicionamientos en el debate sobre la laicidad que actualmente está en curso en

33 Ibidem.: 16.

$34 \mathrm{Tal}$ fue el inicio de la extensa réplica que recibió la ponencia por parte de Diego Peña, con la que se abrió un interesante debate, que ha quedado recogido en la publicación aludida: cf. Ibidem.: 84. 
Europa, creo que se impone la constatación de que esta es una cuestión que obligatoriamente remite a la de si existen fundamentos prepolíticos del estado liberal secularizado vigente en la mayoría de los países occidentales. Tal problema fue tratado en el debate HabermasRatzinger ${ }^{35}$ y ha sido objeto de un particular análisis por parte de Gustavo Zagrebelsky, profesor de Filosofía del Derecho en la Universidad de Turín $^{36}$. Zagrebelsky constata que la afirmación del eminente constitucionalista católico Ernst-Wolfgang Böckenförde, contenida en un ensayo de 1964, fue el punto de partida de Habermas para su debate con Ratzinger en la Academia Católica de Baviera de 2004; esa afirmación merece un análisis pormenorizado que le haga justicia, para no ser reinterpretado de manera interesada, tal y como parece hacerlo, en su opinión, Ratzinger. Para el Cardenal las palabras de Böckenförde darían pie a sostener que el Estado basado en la libertad - en cuanto Estado y no como sociedad- no puede con sus solas fuerzas de hecho garantizar sus propios presupuestos, sino que debe legítimamente buscarlos más allá en el cristianismo. Ello justificaría el requerimiento para la Iglesia Católica de un status diferenciado, que le

35 Habermas, J., Ratzinger, J., Dialéctica de la secularización, Madrid, Ediciones Encuentro, 2006.

36 Zagrebelsky, G., "Sobre el dicho: el estado liberal secularizado vive de presupuestos que él mismo no está en condiciones de garantizar. Este es el gran riesgo que se asume por amor a la libertad" en AA.VV. Entre la ética, la politica y el derecho. Estudios en homenaje al profesor Gregorio Peces-Barba, vol. 1, Madrid, Dikynson, 2008: 1321-1342. 
permitiera ejercer esa función respecto al Estado: la de suministrarle los presupuestos que éste no puede darse a sí mismo.

Tales conclusiones le parecen inadmisibles a Zagrebelsky en virtud de la propia doctrina conciliar de la autonomía de lo temporal. Lo decisivo resulta, pues, delimitar el marco adecuado de relaciones entre los estados y las iglesias, dentro del respeto al pluralismo cosmovisivo, que impide status de privilegio para todas las confesiones religiosas, incluida la cristiana.

En mi opinión, mientras no se entienda que el cristianismo más que una religión junto al resto, es la apuesta por la verdad, no se verá la lógica del razonamiento en el que Ratzinger suele apoyar rigurosamente sus análisis y propuestas sobre filosofía política, que no pueden malinterpretarse como regresivas respecto al Vaticano II, sino que brindan nuevos horizontes de laicidad ${ }^{37}$.

37 Creo que el sustrato teológico de la propuesta de Ratzinger sobre este tema se encuentra desarrollado ampliamente en su libro Ratzinger, J., $F e$, verdad y tolerancia, Salamanca, Ediciones Sígueme, 2005. Cuando uno lee algunas alocuciones pontificias sobre la necesidad de una nueva laicidad, que se asiente en el respeto al derecho natural, como p. ej. el Mensaje para la Jornada Mundial de la paz del año 2006, titulado "La persona humana, corazón de la paz", no puede menos de reconocer en Benedicto XVI al propio Raztinger, en muchas de las intuiciones que contienen sus libros. La más reciente intervención en la que Benedicto XVI ha abordado el tema del laicismo, apostando por un laicidad positiva, fue su discurso del 12 de septiembre de 2008 en París, ante el Presidente de la República Francesa. 
Naturaleza y Libertad. Revista de estudios interdisciplinares. Número 1, 2012. ISSN: 2254-9668

\section{REIVINDICACIÓN DE UNA ANTROPOLOGĹA ADECUADA EN EL} MARCO DEL PLURALISMO COSMOVISIVO Y NECESIDAD DE UNA NUEVA CRÍTICA DE LAS IDEOLOGÍAS

La conjunción de estos tres elementos da como resultado una amalgama ideológica frente a la cual es difícil resistir. Se precisan no sólo argumentos teóricos sólidos, sino capacidad emocional de trasladar a la opinión pública los perjuicios que entraña sucumbir a la ideología dominante, a este political correctness que a todos nos sojuzga. No parece una tarea fácil, pero la filosofía puede contribuir a desenmascarar los engañosos retrocesos históricos y cívicos que supone toda ideología totalitaria. Es preciso distinguir en las sociedades plurales y abiertas entre las legítimas opciones cosmovisivas de sus ciudadanos y las ideologías que pretenden suplantar la libertad, al amparo del legítimo pluralismo ideológico que caracteriza las democracias. Resulta de nuevo necesaria la crítica de las ideologías para evitar los totalitarismos que felizmente fueron superados y denunciados por el fino análisis de Hannah Arendt, allá por el año 1951 en su emblemática obra Los orígenes del totalitarismo.

Lo que conviene advertir es que Arendt no sólo denunció el nazismo, el fascismo y el estalinismo, sino "también lo que podríamos llamar algunos cristales proto-totalitarios o cuasitotalitarios en las democráticas sociedades de masas de los años cincuenta", tales como "el eclipse de la política por la gestión social y la colonización del espacio público por las técnicas científicas de manipulación de la opinión y 
gestión de las poblaciones" ${ }^{38}$. Permaneciendo fiel a esa capacidad herética, por no llamarla políticamente incorrecta, de advertir acerca de los peligros cuasitotalitarios de las sociedades democráticas Arendt consiguió ponernos en guardia frente a los nuevos fenómenos sociales que encierran un tremendo potencial de convertir a los humanos en simples seres superfluos. Lo cierto y verdad es que ese peligro está cada vez más presente en nuestras sociedades, que consiguen someter la libertad humana a la falsa necesidad de una especie de determinismo social, pese a la retórica consabida de la libertad de mercado y la democracia cosmopolita.

Por todo ello resulta necesario preguntarse en tono arendtiano con Nancy Fraser: “¿vivimos realmente en un mundo postotalitario? ¿significa realmente la desaparición primero del fascismo y luego del comunismo el final de los proyectos hiper-totalizadores que podrían destruir el mundo libre y hacer superfluo al ser humano? ¿o más bien están esos proyectos esperando entre bastidores?" ${ }^{39}$. El mero hecho de sospechar la existencia de gérmenes proto-totalitarios en el interior de las sociedades democráticas debe obligarnos a reflexionar sobre las verdaderas causas del malestar de nuestras democracias con más frecuencia de lo habitual ${ }^{40}$.

38 Fraser, N., Escalas de justicia, Barcelona, Herder, 2008: 236.

39 Nancy Fraser titula así el capítulo 8 de la obra citada: "Amenazas a la humanidad en un mundo globalizado: reflexiones arendtianas sobre el siglo XXI". Frazer, 2008: 245.

40 Cf. Pérez-Díaz, V., El malestar de la democracia, Barcelona, Crítica, 2008. 
No es descabellado, por tanto, advertir que la mutua interacción de varios factores puede desencadenar proyectos ideológicos totalitarios más o menos encubiertos. Tal es el análisis al que apunta la conjunción del factor cientifista, pansexualista y laicista que aquí se propone. Para Nancy Fraser los "cristales" proto-totalitarios al inicio del siglo XXI habría que identificarlos con los cuatro factores siguientes:

a) la peligrosa transformación que la globalización está llevando a cabo de las sociedades liberal-democráticas, haciéndolas más vulnerables a las manipulaciones cuasitotalitarias;

b) la emergencia de estructuras postwesfalianas de gobernación a nivel de economía global y derecho internacional;

c) la aparición de panmovimientos regresivos de tipo religioso en los tres monoteísmos;

d) el surgimiento de movimientos transnacionales de tipo emancipador, en el que cabría englobar desde el feminismo internacional al ecologismo, pasando por los movimientos antiglobalización.

Curiosamente no faltan análisis finos y convergentes sobre las amenazas actuales que se ciernen sobre la humanidad del siglo XXI. De todos modos, si tal vez "el siglo XXI todavía está esperando a su propia Hannah Arendt", lo cierto y verdad es que todos coincidiríamos en exclamar: ¡ojalá llegue pronto! ${ }^{41}$

41 Cf. Fraser, 2008: 250. 
Naturaleza y Libertad. Revista de estudios interdisciplinares. Número 1, 2012. ISSN: 2254-9668

Fernando García-Cano Lizcano

Escuela de Arte Pedro Almodóvar

fernando.garciacano@edu.jccm.es 